\title{
Prediction of exertional lower extremity musculoskeletal injury in tactical populations: protocol for a systematic review and planned meta-analysis of prospective studies from 1955 to 2018
}

\author{
Shawn D. Flanagan ${ }^{1 *}$ (D, Kellen T. Krajewski ${ }^{1}$, Aaron M. Sinnott ${ }^{1}$, Caleb D. Johnson ${ }^{1}$, Shawn R. Eagle ${ }^{1}$,
} Alice D. LaGoy ${ }^{1}$, Meaghan E. Beckner ${ }^{1}$, Anne Z. Beethe ${ }^{1}$, Rose Turner ${ }^{2}$, Mita T. Lovalekar ${ }^{1}$, Courtenay Dunn-Lewis ${ }^{1,3}$, Chris Connaboy ${ }^{1}$ and Bradley C. Nindl ${ }^{1}$

\begin{abstract}
Background: Musculoskeletal injuries (MSI) represent more than half of all injuries in tactical populations (i.e., military service and public safety workers including police, firefighters, emergency medical services (EMS)). Most lower extremity MSIs result from physical exertion during training, occupational tasks, and recreation. Such exertional lower extremity injuries (ELEI) produce a significant human and financial cost. Accordingly, significant efforts have been made to identify sensitive, specific, and reliable predictors of ELEl. There is a need to synthesize and evaluate the predictive value of risk factors for ELEI while addressing the influence of occupation, sex, exposure, injury characteristics, and study quality. Therefore, the purpose of this systematic review and planned meta-analysis is to evaluate risk factors for ELEl in tactical populations.
\end{abstract}

Methods: After the development of a search strategy, comprehensive searches will be conducted in MEDLINE, EMBASE, Cochrane, and CINAHL databases. Articles will be screened with a multi-user process and delimited to prospective comparative cohort studies that directly measure injury occurrence in the target population(s). Extracted data will be synthesized and assessed for reporting bias, meta-bias, and overall quality, with subgroup analyses to determine the influence of participant, injury, and exposure characteristics in addition to study quality.

Discussion: This systematic review and planned meta-analysis will comprehensively evaluate ELEl risk factors. Information gained will inform injury prevention protocols, facilitate the use of improved measurements, and identify requirements for future research.

Trial Registration: The systematic review protocol was registered with the International Prospective Register of Systematic Reviews (PROSPERO) on 3 Jan 2018 (registration number CRD42018056977).

Keywords: Biomechanics, Epidemiology, Exercise, Prediction, Knee, Overuse, Performance, Rehabilitation, Risk factors, Training

\footnotetext{
* Correspondence: sdf.29@pitt.edu

${ }^{1}$ Neuromuscular Research Laboratory and Warrior Human Performance

Research Center, Department of Sports Medicine and Nutrition, School of

Health and Rehabilitation Sciences, University of Pittsburgh, Pittsburgh, PA,

USA

Full list of author information is available at the end of the article
}

(c) The Author(s). 2018 Open Access This article is distributed under the terms of the Creative Commons Attribution 4.0 International License (http://creativecommons.org/licenses/by/4.0/), which permits unrestricted use, distribution, and reproduction in any medium, provided you give appropriate credit to the original author(s) and the source, provide a link to the Creative Commons license, and indicate if changes were made. The Creative Commons Public Domain Dedication waiver (http://creativecommons.org/publicdomain/zero/1.0/) applies to the data made available in this article, unless otherwise stated. 


\section{Background}

The threat posed by MSI to the readiness, performance, and long-term health of tactical populations is well-recognized [1-4]. In the U.S. military alone, musculoskeletal injury (MSI) is responsible for nearly $75 \%$ of limited duty cases and costs billions of dollars annually [5-9]. In public safety workers, MSI accounts for more than half of all injuries $[2,10,11]$ with a 4 - to 40 -fold increase in risk compared to other occupations $[4,12]$. The long-term implications of MSI were recently highlighted in a systematic review that identified military, police, and firefighters as being several times more likely to experience knee and hip osteoarthritis compared to controls [13]. Given the prevalence and burden of MSI in tactical populations, significant attention has been placed on the identification of risk factors that predict injury $[3-5,14]$.

Physical exertion (e.g., training, occupational tasks, and recreation) is essential for the development and maintenance of physical performance and fitness, core occupational competencies for tactical populations $[8,15,16]$. Nevertheless, physical exertion is also the leading cause of MSI $[6,7$, $14,17,18]$ with the lower extremities most frequently affected [4, 5, 19-22]. Such exertional lower body injury (ELEI) is associated with previous injury [23-30], female sex [34-43], various lifestyle factors (e.g., smoking) [43], genetic variation in musculoskeletal structures [44-48], neurocognitive function [49-54], and lower physical fitness [30-33]. Paradoxically, while physical fitness is inversely related to ELEI risk, higher training volumes used to improve physical fitness also increase injury risk $[55,56]$. These observations underscore the need to synthesize and evaluate specific aspects of physical exertion (e.g., training mode, volume, load) alone and in combination with other individual, behavioral, environmental, or occupational factors that may moderate ELEI risk in tactical populations [3, 25, 30, 57-63].

A 2003 review of risk factors for lower extremity injury identified a number of limitations in the literature base, including (1) inadequate statistical power, (2) need for comparisons based on sex, (3) confound of unadjusted exposure levels, and (4) inconsistent injury classification schemes [64]. Similarly, the development of increasingly advanced (and accessible) technologies has provided new ways to predict and diagnose MSI $[44,45,65,66]$. As a result, myriad techniques and measures have been promoted as superior predictors of ELEI with little validation and considerable risk of misuse. Thus, there is a need to quantitatively synthesize new evidence, while addressing known limitations of the literature base [13, 67].

In this systematic review and planned meta-analysis, we evaluate prospective studies to determine the predictive value of risk factors for ELEI in tactical populations. A secondary purpose is to perform subgroup analyses to evaluate risk factors based on participant, exposure, injury, and study characteristics. The synthesis of rigorous evidence will clarify generalized predictors of ELEI and identify factors specific to different tactical populations. The findings of this review will support efforts to identify targets for ELEI prevention and the optimization of physical training.

\section{Objectives}

The primary objective of this systematic review is to evaluate predictors of ELEI in military and public safety populations. The proposed systematic review will address the following topics:

1. Determine the most sensitive and specific risk factors for ELEI in military and public safety populations.

2. Assess the influence of different participant and study characteristics on the prediction of ELEI and statistical heterogeneity.

\section{Methods \\ Eligibility criteria}

Studies will be selected based on the following criteria for study design, participants, interventions, comparators, outcomes, and other study traits.

\section{Study designs}

To identify, synthesize, and evaluate risk factors for ELEI, prospective comparative cohort studies will be included. Prospective observational studies will include direct between-group comparisons; single-arm studies will be excluded (e.g., benchmarking, simulated comparisons). Randomized controlled trials (RCTs), retrospective studies, cross-sectional studies, case-control, nested case-control, case reports and series, ideas, opinions, editorials, animal research, and in vitro research will be excluded.

\section{Participants}

Studies on adults aged 18 years or older will be included. Participants must be active military service members or public safety workers (including police, firefighters, and emergency medical services (EMS)). International military members that meet the national age requirement will be included. Studies of the target populations after retirement will be excluded.

\section{Interventions}

Risk factors for ELEI in tactical populations will be evaluated. Acceptable risk factors include continuous, categorical, objective, subjective, modifiable, non-modifiable, internal, or external variables associated with modified risk of injury. Injuries will be identified in accordance with terminology provided by the International Classification of Diseases (ICD-9-M and ICD 10) [68, 69] and National Institute for Occupational Safety 111 and Health (NIOSH) 
[1]. Qualifying injuries will include fractures, derangements, dislocations, sprains, strains, and other injuries or disorders of the muscles, nerves, tendons, joints, or cartilage of the lower limbs. Such injuries must be caused, precipitated, or exacerbated by sudden or prolonged exertion involving movement repetition, force, vibration, or adverse biomechanics. Injuries resulting from falls (parachuting), motor vehicle accidents, violence, external contact, and war will be excluded.

\section{Comparators}

For the analysis of prospective observational studies, controls will include participants who do not experience ELEI.

\section{Outcomes}

Outcomes and their definitions will be collected as reported in individual studies. Dichotomous data will be extracted, reflecting the nature of the disease in question (ELEI incidence). Anticipated measures include incidence, odds ratios, risk ratios, and likelihood ratios. Outcomes may be derived from self-report, medical records, behavioral performance, medical imaging, physiological measurements, and biological specimens. Studies that do not report injury incidence will be excluded. Outcome measurements specific to ELEI will be extracted. Composite and upper body MSI will not be included, and studies that do not report or provide lower body-specific data will be excluded. If ELEI is subdivided by structure, tissue, category, or other factors, all levels of data will be extracted and pooled depending on injury classification.

\section{Timing}

Studies with a minimum surveillance period of 3 months will be prioritized. A 3-month surveillance period was selected to ensure the detection of ELEIs such as tibial stress fractures or subsequent injuries that develop over prolonged periods of time and thus likely underreported during shorter observation periods $[68,69]$. Studies with surveillance durations of at least 2 months will be considered if otherwise acceptable and of sufficient quality as determined by the review team.

\section{Setting}

Study setting is unrestricted.

\section{Language}

Articles reported in English will be included. When applicable, studies involving predominantly non-English speaking populations will be included.

\section{Other review eligibility criteria}

Study inclusion will not be restricted by geographic region. Inclusion will be limited to original research articles published in peer-reviewed journals. Abstracts, unpublished data, commentaries, letters, and conference proceedings will be screened. Data from 1955 to 2018 will be included and evaluated for systematic variation of effect estimates associated with publication age. If affected by publication age, effect estimates may be normalized or subgrouped and analyzed separately.

\section{Information sources}

MEDLINE, EMBASE, Cochrane, and CINAHL electronic databases will be searched. We will also search the reference lists of included publications, relevant reviews, and gray literature. Article listings in the top five journals of included studies will be searched from 2003 to 2018. The final reference list will be circulated among the review team and external experts identified by the team. The search strategy will meet IOM Standards for Systematic Reviews [70].

\section{Search strategy}

The search strategy will use medical subject headings $(\mathrm{MeSH})$ and text words that identify the target populations, injuries and structures, exposures and practices, and analysis features relevant to injury prediction. Searches will be limited to original human research articles published in peer-reviewed journals in English. Searches will be limited to 1955-2018, but not limited for study design. The MEDLINE search strategy will be developed by a health sciences librarian with expertise in systematic review searches (RT) in collaboration with the project team and reviewed by an additional Librarian (see Additional file 1 for search strategy). The MEDLINE search strategy will be adapted for use with EMBASE, Cochrane, and CINAHL databases. The electronic database search will be updated and re-run before the final analysis to capture new studies and confirm retrieval of a high proportion of eligible studies. PROSPERO will be searched for ongoing and completed reviews at the beginning and end of the review process. Recently completed systematic reviews will be searched for new articles.

\section{Study records \\ Data management}

Citation abstracts and full-text articles captured during the literature search will be uploaded into Distiller Systematic Review (DSR) software for screening. Before DSR upload, duplicate search results will be removed using Endnote reference management software. When multiple reports on a study are identified, the study team will assess the consistency of reported study design, sample size, outcome (s), and statistical test (s). All relevant original information will be extracted and collated. In the event of multiple versions, the initial version will be retained. The inclusion and exclusion criteria will be developed into a series of forms for article screening (see 
Additional file 2 for screening forms). The forms will be tested and refined before formal screening. New members of the team will be trained on the content area and DSR software prior to participation.

\section{Selection process}

Titles of studies retrieved from the search will be independently screened by two reviewers for relevance to the prediction of ELEI. Reviewers will be blind to study author (s), journal title, and institution. For level two screening, abstracts will be reviewed for requisite study outcomes. Level three screening will confirm the eligibility of the participant population. After the first three levels of screening, if the initial inclusion criteria are met or inconclusive, the full article will be obtained. At the fourth screening level, the full inclusion criteria will be applied to the text. When questions about eligibility persist, study authors will be contacted for additional information. If the study author does not respond to contact for additional information or the response is deemed inadequate, the study will be screened and reason (s) noted. Disagreements about inclusion will be resolved through discussion or final review by a third author. Reason (s) for excluding articles will be reported. Inter-rater agreement will be analyzed after the completion of three selection process procedures: (1) initial assessment test, (2) refinement, and (3) formal screening process.

\section{Data collection process}

Data will be extracted in duplicate by two independent reviewers using standardized forms in DSR. To improve consistency, data extraction forms will be pre-piloted in conjunction with the selection forms (see Additional file 3 for data extraction forms). Disagreements will be resolved by a third reviewer (SF, CC, CD, and $\mathrm{ML}$ ). When data from primary studies do not present all necessary data, the study authors will be contacted and asked to provide the missing data. We will attempt to contact primary authors up to three times by email or phone. In the event of uncertainty or missing data, failure to respond, comply, or follow-up will result in study exclusion. The original study authors will also be contacted to confirm the accuracy of the final extracted data. When multiple reports of a single study are identified, non-duplicated information will be collated if the observation periods are the same. Otherwise, data from the initial report will be included, with the exclusion of duplicates noted.

\section{Data items}

Extracted data will include study characteristics (study setting and design, sample size, duration of follow-up, methods and intervention details, measurement techniques, and time points), participant and exposure characteristics (occupation, duration of participation, demographic, anthropometric, biological, workload, history, fitness, exertional characteristics), injury characteristics (definition, reporting method, characteristics, location, and subtype, indicators of acceptability), author interpretation (s) of findings, suggested mechanisms of action, potential confounders, and information for the assessment of risk of bias.

Outcomes specific to anatomic structures (e.g., tibia, Achilles tendon, soleus muscle) and disorders (e.g., stress fracture, tendinopathy, and muscle strain) will be collected for further analysis or aggregation. In the health and rehabilitation science literature, MSI is often classified as non-traumatic (overuse) or traumatic (acute) and risk factors are commonly classified as extrinsic/intrinsic and modifiable/non-modifiable. If injury descriptions are consistent across studies, injuries will be subtyped accordingly. Measures of central tendency and variability will be extracted from figures when necessary using plot digitization software. If effect sizes cannot be calculated, study authors will be contacted for additional information.

\section{Outcomes and prioritization \\ Primary outcome}

The primary outcome will be relative measures of effect (i.e., risk ratios, odds ratios, hazard ratios, etc.) based on ELEI incidence rates. All outcomes will be calculated from the total number of participants at each measurement time point. The use of a dichotomous outcome enhances comprehension and is therefore preferred.

\section{Risk of bias}

Two blinded reviewers will independently assess the risk of bias for each included study. Disagreement between the reviewers will be resolved after discussion or final decision by a third reviewer (SF, CC, CD, and ML). To assess the risk of study bias and overall study quality, the following factors will be considered: study participation, study attrition, prognostic factor measurement, outcome measurement, potential confounding factors, statistical analyses, and reporting. Descriptions provided in the study will be collected and scored using the Quality in Prognostic Studies (QUIPS) instrument [71]. The risk of bias will be summarized graphically across studies. The synthesis will include a subgroup analysis to examine the influence of study quality on the overall findings of the review. Low-quality studies may be excluded from the final analysis.

\section{Data synthesis}

Under the assumption of sufficient homogeneity, quantitative analysis of aggregate participant data will be conducted. The planned analytical approach will include a narrative synthesis of the findings from the included studies, structured around the primary predictors of injury, injury characteristics, and target population characteristics. Study results will be dichotomized and expressed as risk 
ratios (RR) with 95\% confidence intervals (CI). Original study authors will be contacted when there are missing data.

The results of included studies will be pooled and analyzed using stratified random-effects meta-analysis in specialized meta-analysis software (RevMAN v5.3; The Cochrane Collaboration). Subgroup and meta-regression (Stata, StataCorp) analyses will be used to determine whether prediction estimates are influenced by potential effect modifiers such as study characteristics and participants characteristics (see the "Subgroup analysis" section below). Statistical heterogeneity will be determined with chi-square $\left(\chi^{2}\right)$ and $I^{2}(0-100 \%)$ statistics, with $\chi^{2} p>0.10$ and $I^{2}>50 \%$ indicative of substantial heterogeneity. Between-study variance $\left({ }_{T}^{2}\right)$ will be assessed in relation to effect size estimates. In the event of substantial or high heterogeneity $\left(I^{2}>75 \%\right)$ [72], sensitivity analysis will be conducted as indicated by subgroup comparisons and QUIPS checklists.

Review results will be ordered by objective. Important comparisons will also be presented based on the availability of data. Results will be presented in narrative text, tables, and figures. Depending on the outcome of sensitivity and subgroup analyses, studies with a high risk of bias may be omitted from the final meta-analysis.

\section{Subgroup analysis}

If the necessary data are available, sources of betweenstudy heterogeneity and the robustness of the meta-analysis will be investigated with sensitivity and subgroup analyses. Potential risk factors and comparisons will be considered on a case-by-case basis depending on the literature base with the maximal feasible amount of data extracted for the following (likely) subgroup analyses:

1. Participant characteristics (sex, age, occupation)

2. Injury location, structure, class (e.g., ankle, calcaneofibular ligament, sprain)

3. Injury subtype (acute vs. non-traumatic)

4. Risk factor presence, magnitude, or class (extrinsic, intrinsic, modifiable, non-modifiable)

5. Surveillance period

6. Study-specific factors
(a) Sample size
(b) Overall study quality
(c) Risk of bias (e.g., all studies versus low bias studies only)
(d) Publication age

\section{Meta-bias}

The possibility of publication and outcome reporting bias will be explored with funnel plots and the QUIPS checklist. Small sample bias will be assessed by comparing fixed effect estimates with the random effects model. The results may be used to re-weigh studies or conduct further subgroup analysis. The analysis and reporting conducted in this review will comply with guidelines provided by the Measurement Tool to Assess Systematic Reviews (AMSTAR-2) [73].

\section{Confidence in cumulative estimate}

The overall quality of the body of evidence will be determined with the Grading of Recommendations Assessment, Development, and Evaluation (GRADE) approach [74]. Studies excluded from the meta-analysis will be excluded from the GRADE assessment. GRADE results will be used to inform conclusions on the overall strength of predictors of ELEI in tactical populations.

\section{Discussion}

This systematic review and planned meta-analysis will evaluate the independent and collective predictive strength of risk factors for ELEI in tactical populations, including Military Service Members, Firefighters, Police, and EMS. Study inclusion will be determined through a rigorous multi-level screening process with comprehensive assessments for quality and bias. Valid and reliable predictors of ELEI will be identified in high-quality prospective studies with direct measures of injury occurrence. Subgroup analyses will examine the influence of prominent injury characteristics, risk factors, and potential sources of heterogeneity. The analysis will provide the fields of health and rehabilitation sciences and human performance optimization with a robust and comprehensive resource to inform future practices and research initiatives. The authors of this effort are committed to a rigorous and transparent systematic review process. For information on compliance with PRIMSA-P review guidelines, see Additional file 4.

\section{Additional files}

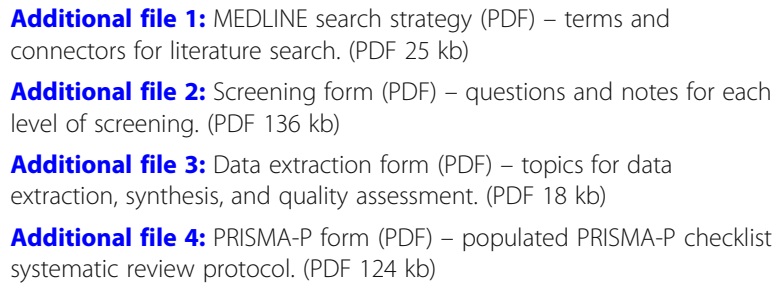

Additional file 3: Data extraction form (PDF) - topics for data extraction, synthesis, and quality assessment. (PDF $18 \mathrm{~kb}$ )

Additional file 4: PRISMA-P form (PDF) - populated PRISMA-P checklist systematic review protocol. (PDF $124 \mathrm{~kb}$ )

\section{Abbreviations}

AMSTAR-2: Measurement Tool to Assess Systematic Reviews; Cl: Confidence intervals; CINAHL: Cumulative Index to Nursing and Allied Health Literature; DSR: Distiller Systematic Review; ELEl: Exertional lower body injury; EMBASE: Excerpta Medica database; EMS: Emergency medical service; GRADE: Grading of Recommendations Assessment, Development, and Evaluation; ICD: International Classification of Diseases; IOM: Institute of Medicine; MEDLINE: U.S. National Library of Medicine bibliographic database; MeSH: Medical subject headings; MSI: Musculoskeletal injury; NIOSH: National Institute for Occupational Safety and Health; PRISMA: Preferred Reporting Items for Systematic Reviews and Meta-Analyses; PROSPERO: International 
prospective register of systematic reviews; QUIPS: Quality in Prognostic Studies; RCT: Randomized controlled trial; RR: Risk ratio

\section{Acknowledgements}

The authors thank Camille Johnson, Alexis Faunce, Brandon Sciavolino, Madeline Wells, Audrey Bentley, Sadhana Sridhar, Megan Magarity, and Daniel Biery for their assistance in level 1-3 screening, and providing critical feedback for the development and refinement of the screening and extraction forms.

\section{Support}

The Neuromuscular Research Laboratory at the University of Pittsburgh sponsors and retains full control of the data. The authors maintain sole responsibility for protocol development, review conduct, data analysis and interpretation, and dissemination. No funding has been received for this study.

\section{Amendments}

If the protocol is amended, the date, description, and rationale of change (s) will be provided in this section. Changes will not be incorporated into the protocol. SF will be responsible for the approval, documentation, and implementation of amendment (s).

\section{Funding}

Not applicable.

\section{Authors' contributions}

SF is the guarantor. SF, CC, CD, KK, AS, CJ, AB, SE, MB, AL, and BN drafted the manuscript. All authors contributed to the development of the selection criteria, bias assessment strategy, and data extraction criteria. RT developed the search strategy. ML provided statistical expertise. CC and BN provided expertise on lower body injury in tactical populations. All authors read, provided feedback, and approved the final manuscript.

\section{Ethics approval and consent to participate}

Not applicable.

\section{Consent for publication}

Not applicable.

\section{Competing interests}

The authors declare that they have no competing interests.

\section{Publisher's Note}

Springer Nature remains neutral with regard to jurisdictional claims in published maps and institutional affiliations.

\section{Author details}

${ }^{1}$ Neuromuscular Research Laboratory and Warrior Human Performance Research Center, Department of Sports Medicine and Nutrition, School of Health and Rehabilitation Sciences, University of Pittsburgh, Pittsburgh, PA, USA. ${ }^{2}$ Health Sciences Library System, University of Pittsburgh, Pittsburgh, PA, USA. ${ }^{3}$ Department of Health and Physical Activity, School of Education, University of Pittsburgh, Pittsburgh, PA, USA.

\section{Received: 15 December 2017 Accepted: 13 November 2018}

Published online: 23 December 2018

\section{References}

1. Health NIfOSa. Musculoskeletal health program: centers for disease control and prevention; 2017. [cited 2017 May 20]. Available from: https://www.cdc. gov/niosh/programs/msd/.

2. Maguire BJ, Smith S. Injuries and fatalities among emergency medical technicians and paramedics in the United States. Prehosp Disaster Med. 2013;28(4):376-82. Epub 2013/05/11. PubMed PMID: 23659321.

3. Bulzacchelli MT, Sulsky SI, Rodriguez-Monguio R, Karlsson LH, Hill MO. Injury during U.S. Army basic combat training: a systematic review of risk factor studies. Am J Prev Med. 2014:47(6):813-822. Epub 2014/12/03. PubMed PMID: 25455122
4. Gray SE, Collie A. The nature and burden of occupational injury among first responder occupations: a retrospective cohort study in Australian workers. Injury. 2017:48(11):2470-7. Epub 2017/10/02. PubMed PMID: 28964511.

5. Hauret KG, Jones BH, Bullock SH, Canham-Chervak M, Canada S. Musculoskeletal injuries description of an under-recognized injury problem among military personnel. Am J Prev Med 2010;38(1 Suppl):S61-S70. PubMed PMID: 20117601.

6. Jones BH, Canham-Chervak M, Canada S, Mitchener TA, Moore S. Medical surveillance of injuries in the US military descriptive epidemiology and recommendations for improvement. Am J Prev Med 2010;38(1 Suppl):S42S60. PubMed PMID: 20117600.

7. Jones BH, Knapik JJ. Physical training and exercise-related injuries. Surveillance, research and injury prevention in military populations. Sports Med 1999:27(2):111-125. PubMed PMID: 10091275.

8. Nindl BC, Williams TJ, Deuster PA, Butler NL, Jones BH. Strategies for optimizing military physical readiness and preventing musculoskeletal injuries in the 21st century. US Army Med Dep J. 2013;Oct-Dec:5-23. PubMed PMID: 24146239.

9. Ruscio BA, Jones BH, Bullock SH, Burnham BR, Canham-Chervak M, Rennix CP, Wells TS, Smith JW. A process to identify military injury prevention priorities based on injury type and limited duty days. Am J Prev Med 2010; 38(1 Suppl):S19-S33. PubMed PMID: 20117593.

10. NIST. The Economic Consequences of Firefighter Injuries and their prevention: Final Report. 2004.

11. Haynes HJM, J. L. U.S. Firefighter Injuries - 2015. National Fire Protection Association, 2016 Oct 2016. Report No.

12. IAo F. Death and injury survey Washington, DC: International Association of Firefighters. Washington: DC; 1998. p. 1999.

13. Cameron KL, Driban JB, Svoboda SJ. Osteoarthritis and the tactical athlete: a systematic review. J Athl Train 2016;51(11):952-961. PubMed PMID: PMC5224737.

14. Jones BH, Hauschild VD. Physical Training, Fitness, and injuries: lessons learned from military studies. J Strength Cond Res 2015;29 Suppl 11:S57S64. PubMed PMID: 26506200.

15. Abt J, Sell TC, Crawford K, Lovalekar M, Nagai T, Deluzio JB, Smalley BW, McGrail MA, Rowe RS, Cardin S, Lephart SM. Warrior model for human performance and injury prevention: eagle tactical athlete program (ETAP) part II. J Spec Oper Med. 2010;10(4):22-33.

16. Nindl B, Eagle SR, Frykman PN, Palmer C, Lammi E, Reynolds K, Allison K, Harman E. Functional physical training improves women's military occupational performance. J Sci Med Sport. 2017;20:591-s7.

17. Poplin GS, Harris RB, Pollack KM, Peate WF, Burgess JL. Beyond the fireground: injuries in the fire service. Injury Prevention. 2012;18(4):228-33.

18. Hootman JM, Dick R, Agel J. Epidemiology of collegiate injuries for 15 sports: summary and recommendations for injury prevention initiatives. J Athl Train 2007:42(2):311-319. PubMed PMID: PMC1941297.

19. Fischer F, Hoser C, Blank C, Schobersberger W, Hepperger C, Gföller P, Fink C. Injuries in Austrian Football Players: Are they an Issue? Sportverletz Sportschaden 2018. Epub 2018/03/12. PubMed PMID: 29529694.

20. Roos KG, Marshall SW, Kerr ZY, Golightly YM, Kucera KL, Myers JB, Rosamond WD, Comstock RD. Epidemiology of overuse injuries in collegiate and high school athletics in the United States. Am J Sports Med 2015;43(7):17901797. PubMed PMID: 25930673.

21. Cook JL, Khan KM, Maffulli N, Purdam C. Overuse tendinosis, not tendinitis part 2: applying the new approach to patellar tendinopathy. Phys Sportsmed 2000;28(6):31-46. PubMed PMID: 20086644

22. Witvrouw E, Bellemans J, Lysens R, Danneels L, Cambier D. Intrinsic risk factors for the development of patellar tendinitis in an athletic population. A two-year prospective study. Am J Sports Med 2001;29(2):190-195. PubMed PMID: 11292044.

23. Ross J, Woodward A. Risk factors for injury during basic military training. Is there a social element to injury pathogenesis? J Occup Med 1994;36(10): 1120-1126. Epub 1994/10/01. PubMed PMID: 7830171.

24. Kaufman KR, Brodine S, Shaffer R. Military training-related injuries: surveillance, research, and prevention. Am J Prev Med 2000;18(3 Suppl):5463. Epub 2000/03/29. PubMed PMID: 10736541

25. Mattila VM, Niva M, Kiuru M, Pihlajamaki H. Risk factors for bone stress injuries: a follow-up study of 102,515 person-years. Med Sci Sports Exerc 2007;39(7):1061-1066. Epub 2007/06/29. PubMed PMID: 17596772.

26. Knapik JJ, Graham B, Cobbs J, Thompson D, Steelman R, Jones BH. A prospective investigation of injury incidence and injury risk factors among Army recruits in military police training. BMC Musculoskelet Disord 2013;14: 32. Epub 2013/01/19. PubMed PMID: 23327563. 
27. Knapik JJ, Graham B, Cobbs J, Thompson D, Steelman R, Jones BH. A prospective investigation of injury incidence and risk factors among army recruits in combat engineer training. Journal of occupational medicine and toxicology (London, England). 2013;8(1):5. Epub 2013/03/19. PubMed PMID: 23497620.

28. Toohey LA, Drew MK, Cook JL, Finch CF, Gaida JE. Is subsequent lower limb injury associated with previous injury? A systematic review and meta-analysis. Br J Sports Med. 2017;51(23):1670-8. Epub 2017/08/09. PubMed PMID: 28784622.

29. Hill OT, Bulathsinhala L, Scofield DE, Haley TF, Bernasek TL. Risk factors for soft tissue knee injuries in active duty U.S. Army soldiers, 2000-2005. Mil Med 2013;178(6):676-682. Epub 2013/06/13. PubMed PMID: 23756076.

30. Hegedus EJ, McDonough S, Bleakley C, Baxter GD, DePew JT, Bradbury I, Cook C. Physical performance tests predict injury in National Collegiate Athletic Association athletes: a three-season prospective cohort study. $\mathrm{Br}$ J Sports Med. 2016;50(21):1333-7. Epub 2016/01/10. PubMed PMID: 26746910.

31. Knapik JJ, Cosio-Lima LM, Reynolds KL, Shumway RS. Efficacy of functional movement screening for predicting injuries in coast guard cadets. J Strength Cond Res 2015:29(5):1157-1162. Epub 2014/09/30. PubMed PMID: 25264669.

32. Peate WF, Bates G, Lunda K, Francis S, Bellamy K. Core strength: a new model for injury prediction and prevention. Journal of occupational medicine and toxicology (London, England). 2007;2:3. Epub 2007/04/13. PubMed PMID: 17428333.

33. Bonazza NA, Smuin D, Onks CA, Silvis ML, Dhawan A. Reliability, validity, and injury predictive value of the functional movement screen: a systematic review and meta-analysis. Am J Sports Med 2017:45(3):725-732. Epub 2016/ 05/10. PubMed PMID: 27159297.

34. Scott SA, Simon JE, Van Der Pol B, Docherty CL. Risk factors for sustaining a lower extremity injury in an Army reserve officer training corps cadet population. Mil Med 2015;180(8):910-916. PubMed PMID: 26226535.

35. Epstein Y, Fleischmann C, Yanovich R, Heled Y. Physiological and medical aspects that put women soldiers at increased risk for overuse injuries. J Strength Cond Res 2015;29 Suppl 11:S107-S110. PubMed PMID: 26506172.

36. Roy TC, Knapik JJ, Ritland BM, Murphy N, Sharp MA. Risk factors for musculoskeletal injuries for soldiers deployed to Afghanistan. Aviat Space Environ Med 2012;83(11):1060-1066. Epub 2012/11/20. PubMed PMID: 23156094.

37. Roy TC, Songer T, Ye F, LaPorte R, Grier T, Anderson M, Chervak M. Physical training risk factors for musculoskeletal injury in female soldiers. Mil Med 2014:179(12):1432-1438. Epub 2014/12/04. PubMed PMID: 25469963.

38. Roy TC, Piva SR, Christiansen BC, Lesher JD, Doyle PM, Waring RM, Irrgang JJ, Moore CG, Brininger TL, Sharp MA. Heavy loads and lifting are risk factors for musculoskeletal injuries in deployed female soldiers. Mil Med 2016; 181(11):e1476-e1e83. Epub 2016/11/17. PubMed PMID: 27849479.

39. Shaffer RA, Rauh MJ, Brodine SK, Trone DW, Macera CA. Predictors of stress fracture susceptibility in young female recruits. Am J Sports Med 2006;34(1): 108-115. Epub 2005/09/20. PubMed PMID: 16170040

40. Lincoln AE, Smith GS, Amoroso PJ, Bell NS. The natural history and risk factors of musculoskeletal conditions resulting in disability among US Army personnel. Work 2002;18(2):99-113. Epub 2002/11/21. PubMed PMID: 12441574

41. Lauder TD, Baker SP, Smith GS, Lincoln AE. Sports and physical training injury hospitalizations in the army. Am J Prev Med 2000;18(3 Suppl):118128. Epub 2000/03/29. PubMed PMID: 10736548

42. Anderson MK, Grier T, Dada EO, Canham-Chervak M, Jones BH. The role of gender and physical performance on injuries: an Army study. Am J Prev Med 2017;52(5):e131-e1e8. Epub 2016/12/26. PubMed PMID: 28012810.

43. Anderson MK, Grier T, Canham-Chervak M, Bushman TT, Jones BH. Physical training, smoking, and injury during deployment: a comparison of men and women in the US Army. US Army Medical Department J. 2015;Apr-Jun:4248. PubMed PMID: 26101905

44. Pistoia W, Van Rietbergen B, Laib A, Ruegsegger P. High-resolution three dimensional $\mathrm{PQCT}$ images can be an adequate basis for in-vivo microFE analysis of bone. J Biomech. 2001;123:176-83.

45. Pistoia W, Van Rietbergen B, Eckstein F, Lill C, Lochmuller EM, Ruegsegger P. Prediction of distal radius failure with microFE models based on 3d-PQCT scans. Adv Exp Med Biol 2001;496:143-151. Epub 2002/01/11. PubMed PMID: 11783616.

46. Kim SK, Roos TR, Roos AK, Kleimeyer JP, Ahmed MA, Goodlin GT, Fredericson M, loannidis JP, Avins AL, Dragoo JL. Genome-wide association screens for Achilles tendon and ACL tears and tendinopathy. PLoS One 2017:12(3):e0170422. Epub 2017/03/31. PubMed PMID: 28358823.

47. Brown KL, Seale KB, El Khoury LY, Posthumus M, Ribbans WJ, Raleigh SM, Collins M, September AV. Polymorphisms within the COL5A1 gene and regulators of the extracellular matrix modify the risk of Achilles tendon pathology in a British casecontrol study. J Sports Sci 2017;35(15):1475-1483. Epub 2016/08/20. PubMed PMID: 27541197
48. Varley I, Hughes DC, Greeves JP, Stellingwerff T, Ranson C, Fraser WD, Sale C. The association of novel polymorphisms with stress fracture injury in elite athletes: further insights from the SFEA cohort. J Sci Med Sport. 2018;21(16): 564-8. Epub 2017/11/14. PubMed PMID: 29129460.

49. Bedno S, Hauret K, Loringer K, Kao TC, Mallon T, Jones B. Effects of personal and occupational stress on injuries in a young, physically active population: a survey of military personnel. Mil Med 2014;179(11):1311-1318. PubMed PMID: 25373060.

50. Pietrosimone B, Golightly YM, Mihalik JP, Guskiewicz KM. Concussion frequency associates with musculoskeletal injury in retired NFL players. Med Sci Sports Exerc 2015;47(11):2366-2372. PubMed PMID: 25871466.

51. Swanik CB. Brains and sprains: the brain's role in noncontact anterior cruciate ligament injuries. J Athl Train 2015;50(10):1100-1102. PubMed PMID: 26340611.

52. Swanik CB, Covassin T, Stearne DJ, Schatz P. The relationship between neurocognitive function and noncontact anterior cruciate ligament injuries. Am J Sports Med 2007;35(6):943-948. PubMed PMID: 17369562

53. Wilkerson GB. Neurocognitive reaction time predicts lower extremity sprains and strains. International Journal of Athletic Therapy and Training. 2012;17(6):4-9.

54. Wilkerson GB, Simpson KA, Clark RA. Assessment and training of visuomotor reaction time for football injury prevention. J Sport Rehabil. 2017;26(1):26-34. PubMed PMID: 26797726.

55. Rutland M, O'Connell D, Brismee JM, Sizer P, Apte G, O'Connell J. Evidencesupported rehabilitation of patellar tendinopathy. N Am J Sports Phys Ther 2010;5(3):166-178. PubMed PMID: 21589672

56. Scott A, Backman $\sqcup$, Speed C. Tendinopathy: update on pathophysiology. J Orthop Sports Phys Ther 2015;45(11):833-841. PubMed PMID: 26390273

57. Gu JK, Charles LE, Andrew ME, Ma CC, Hartley TA, Violanti JM, Burchfiel CM. Prevalence of work-site injuries and relationship between obesity and injury among U.S. workers: NHIS 2004-2012. J Saf Res 2016;58:21-30. Epub 2016/ 09/14. PubMed PMID: 27620931.

58. Smith DL. Firefighter fitness: improving performance and preventing injuries and fatalities. Curr Sports Med Rep 2011;10(3):167-172. Epub 2011/05/31. PubMed PMID: 21623308.

59. Poplin GS, Roe DJ, Peate W, Harris RB, Burgess JL. The association of aerobic fitness with injuries in the fire service. Am J Epidemiol. 2013;179(2):149-55.

60. Knapik JJ, Sharp MA, Canham-Chervak M, Hauret K, Patton JF, Jones BH. Risk factors for training-related injuries among men and women in basic combat training. Med Sci Sports Exerc. 2001;33(6):946-54. Epub 2001/06/19. PubMed PMID: 11404660.

61. de la Motte SJ, Gribbin TC, Lisman P, Murphy K, Deuster PA. A systematic review of the association between physical fitness and musculoskeletal injury risk: part 2 - muscular endurance and muscular strength. J Strength Cond Res. 2017:31(11):3218-34. Epub 2017/08/11. PubMed PMID: 28796127.

62. Jenkins N, Smith G, Stewart S, Kamphuis C. Pre-employment physical capacity testing as a predictor for musculoskeletal injury in paramedics: a review of the literature. Work 2016;55(3):565-575. Epub 2016/10/30. PubMed PMID: 27792024.

63. Lisman PJ, de la Motte SJ, Gribbin TC, Jaffin DP, Murphy K, Deuster PA. A systematic review of the association between physical fitness and musculoskeletal injury risk: part 1-cardiorespiratory endurance. J Strength Cond Res 2017;31(6):1744-1757. Epub 2017/05/26. PubMed PMID: 28538328.

64. Murphy DF, Connolly DA, Beynnon BD. Risk factors for lower extremity injury: a review of the literature. Br J Sports Med 2003;37(1):13-29. Epub 2003/01/28. PubMed PMID: 12547739.

65. Boutroy S, Van Rietbergen B, Somay-Rendu E, Munoz F, Bouxsein ML, Delmas PD. Finite element analysis based on in vivo hr-pQCT images of the distal radius is associated with wrist fracture in postmenopausal women. J Bone Miner Res. 2008;23:392-9.

66. Muller M, Mitton D, Moilanen P, Bousson V, Talmant M, Laugier P. Prediction of bone mechanical properties using QUS and PQCT: study of the human distal radius. Med Eng Phys. 2007;30(8):761-7.

67. Reichelt PA, Conrad KM. Musculoskeletal injury: ergonomics and physical fitness in firefighters. Occup Med (Philadelphia, Pa). 1995;10(4):735-746. Epub 1995/10/01. PubMed PMID: 8903746.

68. Rauh MJ, Macera CA, Trone DW, Shaffer RA, Brodine SK. Epidemiology of stress fracture and lower-extremity overuse injury in female recruits. Med Sci Sports Exerc 2006;38(9):1571-1577. Epub 2006/09/09. PubMed PMID: 16960517.

69. Warden SJ, Burr DB, Brukner PD. Stress fractures: pathophysiology, epidemiology, and risk factors. Current osteoporosis reports 2006;4(3):103109. Epub 2006/08/16. PubMed PMID: 16907999.

70. Eden J, Levit L, Berg A, Morton S, editors. Finding what works in health care: standards for systematic reviews. Washington (DC); 2011. 
71. Hayden JA, van der Windt DA, Cartwright JL, Cote P, Bombardier C. Assessing bias in studies of prognostic factors. Ann Intern Med 2013;158(4): 280-286. Epub 2013/02/20. PubMed PMID: 23420236.

72. Higgins JPT, Thompson SG, Deeks JJ, Altman DG. Measuring inconsistency in meta-analyses. BMJ . 2003;327(7414):557-560. PubMed PMID: PMC192859.

73. Shea BJ, Reeves BC, Wells G, Thuku M, Hamel C, Moran J, Moher D, Tugwell P, Welch V, Kristjansson E, Henry DA. AMSTAR 2: a critical appraisal tool for systematic reviews that include randomised or non-randomised studies of healthcare interventions, or both. BMJ 2017;358:4008. Epub 2017/09/25. PubMed PMID: 28935701.

74. Atkins D, Best D, Briss PA, Eccles M, Falck-Ytter Y, Flottorp S, Guyatt GH, Harbour RT, Haugh MC, Henry D, Hill S, Jaeschke R, Leng G, Liberati A, Magrini N, Mason J, Middleton P, Mrukowicz J, O'Connell D, Oxman AD, Phillips B, Schunemann HJ, Edejer T, Varonen H, Vist GE, Williams JW, Jr., Zaza S, Group GW. Grading quality of evidence and strength of recommendations. BMJ 2004;328(7454):1490. Epub 2004/06/19. PubMed PMID: 15205295

Ready to submit your research? Choose BMC and benefit from:

- fast, convenient online submission

- thorough peer review by experienced researchers in your field

- rapid publication on acceptance

- support for research data, including large and complex data types

- gold Open Access which fosters wider collaboration and increased citations

- maximum visibility for your research: over $100 \mathrm{M}$ website views per year

At BMC, research is always in progress.

Learn more biomedcentral.com/submissions 